\title{
Avaliação de testes imunológicos para o diagnóstico da neurocisticercose
}

\author{
Evaluation of immunological tests for the diagnosis of neurocysticercosis
}

\author{
Heloisa Werneck de Macedo ${ }^{1}$ \\ Regina Helena Saramago Peralta ${ }^{2}$ \\ Armando Cipriano ${ }^{3}$ \\ Maria Rosa Sarmento ${ }^{4}$ \\ Adelaide José $\mathrm{Vaz}^{5}$ \\ José Mauro Peralta ${ }^{6}$
}

\begin{tabular}{|c|c|}
\hline unitermos & resumo \\
\hline $\begin{array}{l}\text { Neurocisticercose } \\
\text { Imunodiagnóstico } \\
\text { Antígeno }\end{array}$ & $\begin{array}{l}\text { Introdução: O diagnóstico da neurocisticercose (NCC) deve ser feito pela associação de técnicas } \\
\text { de imagem com métodos imunológicos sensíveis e específicos. Objetivos: Avaliar os métodos Elisa } \\
\text { e Western blot (Wb), utilizando-se como antígeno extrato bruto salino da larva da Taenia solium, } \\
\text { o Cysticercus cellulosae e Wb, empregando-se como antígeno cisticercos da Taenia crassiceps em } \\
\text { amostras de soro, para o diagnóstico da NCC. Materiais e métodos: Foram avaliadas amostras de } \\
\text { soro de } 43 \text { pacientes com diagnóstico de NCC: } 21 \text { por clínica, tomografia computadorizada de } \\
\text { crânio (TC) e presença de anticorpos anticisticerco no líquido cefalorraquiano (LCR); } 22 \text { por } \\
\text { clínica e TC e } 229 \text { pacientes com diferentes parasitoses. Para as análises desses materiais } \\
\text { biológicos foram empregados os métodos Elisa, usando-se como antígeno C. cellulosae, e Wb, } \\
\text { usando-se como antígeno C. cellulosae e Cysticercus longicollis. Resultados: O método Elisa } \\
\text { utilizando C. cellulosae como antígeno apresentou especificidade de } 95 \% \text { e sensibilidade de } 71 \% \text {. } \\
\text { O método Wb utilizando C. cellulosae ou C. longicollis como antígeno apresentou sensibilidade de } \\
86 \% \text { e especificidade de } 99 \% \text {. Conclusões: Os métodos imunológicos no LCR são importantes } \\
\text { para a definição da NCC. Entretanto o método Elisa no soro ainda não é adequado pela sua baixa } \\
\text { sensibilidade, mas o Wb apresentou alta especificidade e boa sensibilidade, podendo auxiliar no } \\
\text { diagnóstico da NCC, possibilitando sugerir a existência de forma transicional da doença, não } \\
\text { demonstrada pela TC. }\end{array}$ \\
\hline
\end{tabular}

abstract

Background: The diagnosis of neurocysticercosis (NCC) has been made by association of neuroimaging studies and use of sensitive and specific serological assays. Objectives: Evaluating Elisa and Western blot (Wb) tests using a crude extract of Cysticercus cellulosae (Taenia solium) as antigen and a Wb test using a glycoprotein of Cysticercus longicollis (Taenia crassiceps) as antigen for the diagnosis of NCC. Methods: Serum samples from 43 patients with NCC: 21 patients presenting clinical manifestations, cerebral computed tomography findings compatible with cerebral lesions and high levels of anti-cysticercus antibodies in cerebrospinal fluid (CSF); 22 patients with clinical manifestations and cerebral computed tomography findings compatible with cerebral lesions and serum samples from

229 patients with other parasitic infections were tested by Elisa standardized with crude extract of $\mathrm{C}$. cellulosae and Wb standardized with glicoprotein of $\mathrm{C}$. cellulosae and $\mathrm{C}$. longicollis. Results: The Elisa test using crude extract of C. cellulosae showed specificity of $95 \%$ and sensibility of $71 \%$. Both tests using glycoproteins of either C. cellulosae or C. longicollis showed specificity of $99 \%$ and sensibility of $86 \%$. Conclusions: The use of immunological techniques for antibodies detection in CSF was shown to be an important tool for NCC diagnosis. However, detection of antibodies in serum lacked sensibility when Elisa was evaluated. The Wb assay in serum samples was sensitive and specific and it can be helpful for the diagnosis of the transitional form of NCC frequently not detected by cerebral computed tomography.

\section{key words}

Neurocysticercosis

Immunodiagnosis

Antigen 


\section{Introdução}

A neurocisticercose (NCC) é causada pela presença da larva da T. solium, o C. cellulosae, no sistema nervoso central (SNC).

O diagnóstico desta doença tem sido feito através de técnicas de imagem, mas estas podem fornecer resultados falso-negativos $(18,26,27)$. Por isso é necessária a associação de métodos imunológicos que apresentem altas sensibilidade e especificidade para o diagnóstico da NCC. Eles são também importantes na avaliação da quebra da barreira hematencefálica e da produção intratecal de imunoglobulinas $(11,14,25)$.

Técnicas sorológicas com elevadas sensibilidade e especificidade permitem o diagnóstico da cisticercose causada pela presença de cistos em diferentes localizações $(29,42)$, além de poderem ser utilizadas em estudos epidemiológicos $(24,28)$. Atualmente, o método mais empregado para a detecção de anticorpos para C. cellulosae é o imunoenzimático (Elisa), tanto no soro como no LCR $(4,7,12,22)$. Outro método imunoenzimático que vem sendo utilizado no diagnóstico das cisticercoses humana e suína (35) é o Western blot (Wb). Entre os diferentes antígenos testados, aqueles ricos em glicoproteínas, obtidos a partir de C. cellulosae, é que têm demonstrado maior sensibilidade $(23,34-36)$.

Após a observação da existência de antígenos comuns entre as larvas de $T$. solium e $T$. crassiceps, um cestodário parasita de raposas, cuja forma larvária, o C. longicollis, tem sido encontrada em pequenos roedores e se reproduz por brotamento, estes cisticercos passaram a ser bastante estudados como fonte de antígenos para métodos imunológicos utilizados no diagnóstico da NCC (3, 38-40).

A proposta deste trabalho foi avaliar dois métodos imunológicos para o diagnóstico da NCC: Elisa, utilizando-se como antígeno extrato bruto salino de $C$. cellulosae; e Wb, empregando-se como antígeno $C$. longicollis.

\section{Materiais e métodos}

\section{Casuística}

Foram analisadas amostras de soro de 21 pacientes com achados clínicos e laboratoriais de NCC (TC e presença de anticorpos anticisticerco no LCR); 22 pacientes com NCC diagnosticada por clínica e TC; 229 indivíduos com diferentes parasitoses e 14 voluntários (controles negativos).

\section{Diagnóstico laboratorial}

\section{Método imunoenzimático Elisa para detecção de anticorpos anticisticerco no soro (Elisa-Cc)}

Foi padronizado em nosso laboratório um método Elisa para determinação de anticorpos ( $\lg G$ ) para cisticercose, com antígeno preparado de macerado de cisticercos extraídos de carne de suíno contaminada com larvas de T. solium (extrato total salino) (37). Foram utilizadas placas plásticas de microtitulação (Nunc-Immuno modules, Nalg Nunc International, Roskilte, Denmark). As cavidades das placas foram recobertas com o antígeno diluído em tampão carbonato $(0,05 \mathrm{M})$, pH 9,6, na concentração de $5 \mu \mathrm{g} / \mathrm{ml}$. Após um período de incubação de $1 \mathrm{~h}$ a $37^{\circ} \mathrm{C}$, foram efetuadas três lavagens com PBS $\left(\mathrm{Na}_{2} \mathrm{HPO}_{4}\right.$ $0,0075 \mathrm{M} ; \mathrm{NaH}_{2} \mathrm{PO}_{4} 0,0025 \mathrm{M} ; \mathrm{NaCl} 0,15 \mathrm{M} \mathrm{pH} 7,2$ ) contendo $0,3 \%$ de Tween 20 . Soros de pacientes e de controles foram diluídos a 1:100 e LCR a 1:2, em PBS contendo $0,3 \%$ de Tween e $5 \%$ de leite desnatado (PBS/T/LD), e $100 \mu \mathrm{l}$ das diluições foram adicionados a cada cavidade. Após incubação de 30 minutos a $37^{\circ} \mathrm{C}$, as cavidades foram lavadas seis vezes; então, adicionaram-se $100 \mu \mathrm{l}$ de IgG de cabra anti-lgG humana conjugada à peroxidase (Biolab-Mérieux, Rio de Janeiro, Brasil), diluída em $\mathrm{PBS} / \mathrm{T} / \mathrm{LD}$, a uma concentração de 1:10.000. A placa foi, então, novamente incubada a $37^{\circ} \mathrm{C}$ por 30 minutos, lavada nove vezes, sendo, a seguir, adicionados $100 \mu$ l da solução reveladora, preparada no momento de uso, como se segue: TMB (3', 3', 5', 5'tetrametilbenzidina) (Sigma) + DMSO (dimetilsulfóxido) (Sigma) na concentração de $10 \mathrm{mg} / \mathrm{ml}$ + $20 \mu \mathrm{l}$ de uma solução de $\mathrm{H}_{2} \mathrm{O}_{2}$ (peróxido de hidrogênio) a $3 \%$ adicionados a $10 \mathrm{ml}$ de tampão citrato-fosfato pH 5,5 (citrato $0,1 \mathrm{M}$; fosfato de sódio $0,2 \mathrm{M}$ ). A reação se processou no escuro por 15 minutos, em temperatura ambiente, adicionando-se posteriormente, a cada orifício, $100 \mu \mathrm{l}$ de $\mathrm{H}_{2} \mathrm{SO}_{4}$ (ácido sulfúrico) $1 \mathrm{~N}$. A leitura das amostras foi efetuada em espectrofotômetro para placas de microtitulação (Bio-Rad, Model 3550 UV), na faixa de $450 \mathrm{~nm}$.

Em todos os testes foram incluídos controles positivos em duplicata, controles negativos em triplicata, controle do conjugado (cavidade onde não se adicionou soro ou LCR) e controle da placa (cavidade onde não se adicionou o antígeno). Todos os soros foram mantidos a $-20^{\circ} \mathrm{C}$ até serem usados.

Os valores do limiar de reatividade (cut-off) para o método Elisa com antígeno de C. cellulosae em amostras de soro foram determinados em um ensaio de padroniza- 
ção. Ajustou-se uma distribuição normal aos resultados do Elisa de 11 amostras de soro de pacientes com NCC comprovada (controles positivos) e de 28 amostras de soro de indivíduos saudáveis (controles negativos). As médias e desvios padrões das densidades óticas (DO) obtidas para os controles foram: $1,179 \pm 0,200$ para os controles positivos e 0,213 $\pm 0,154$ para os controles negativos. Verificando-se que, nas condições dos ensaios de padronização, as duas curvas se cruzam com resultado igual a 0,633 (cut-off), com nível de confiança de $99,7 \%$, estabeleceu-se a relação entre o valor do cut-off e as médias dos valores dos controles positivos e negativos, como se segue:

$\frac{\bar{X}_{C P}-\bar{X}_{C N}}{\text { cut-off }-\bar{X}_{C N}}=2,3$

cut-off $=\bar{X}_{C N}+\frac{\bar{X}_{C P}-\bar{X}_{C N}}{2,3}=0,633$

onde $\overline{\mathrm{X}}=$ média; $\mathrm{CN}=$ controles negativos; $\mathrm{CP}=$ controles positivos.

Sendo $S$ = desvio padrão, a probabilidade de uma amostra negativa apresentar um valor acima de $\bar{X}_{\mathrm{CN}}+2,73 \mathrm{~S}_{\mathrm{CN}}$ é a mesma que a de uma amostra positiva apresentar um valor abaixo de $\bar{X}_{C P}-2,73 S_{C P}$ igual a $0,3 \%$.

Selecionou-se um par de amostras de controles positivo e negativo que atendesse à relação anteriormente descrita para fins de controle e ajuste do valor de cut-off em cada experimento a ser realizado posteriormente. Ensaios prévios estabeleceram as faixas de $\bar{X} \pm 3 S$ (probabilidade de $99,7 \%)$ para validação dos resultados de cada experimento:

- controle negativo: 0,08-0,19

- controle positivo: 1,16-1,7

- cut-off: 0,55-0,85

Em cada ensaio foram incluídas amostras de um controle positivo e de um controle negativo usadas no ensaio de padronização. Os resultados foram expressos em unidade imunoenzimática (UE) arbitrariamente definida, a qual reflete porcentagem de reatividade das amostrasteste em relação ao valor do cut-off referência, como se segue:

cut-off referência $=\mathrm{CN}+\frac{\mathrm{CP}-\mathrm{CN}}{2,3}$

$\mathrm{UE}=\frac{\text { valor da amostra }}{\text { cut-off referência }} \times 100$
As amostras foram classificadas como positivas quando os resultados eram superiores a 100 UE.

\section{Método Western blot com antígeno de C. cellulosae para detecção de anticorpos anticisticerco no soro $(W b-C c)$}

Como segundo método para detectar anticorpos $\lg \mathrm{C}$ anticisticerco no soro foi utilizado o conjunto comercial Cysticercosis Western Blot Assay Kit (Immunonetics. Cambridge, MA, EUA), segundo instruções do fabricante.

\section{Método Western blot com antígeno de $\mathrm{C}$. longicollis para detecção de anticorpos anticisticerco no soro (Wb-Cl)}

O método Wb com antígeno de $C$. longicollis foi padronizado em nosso laboratório para detecção de anticorpos $\lg \mathrm{G}$ anticisticerco no soro.

\section{Preparo do antígeno}

O antígeno foi preparado a partir de C. longicollis. A cepa ORF foi mantida em camundongos fêmeas BALB/C com idade entre oito e 12 semanas, por inoculação intraperitoneal de cinco parasitos de pequeno tamanho e que não apresentavam brotamento. Após 90 dias, os animais que apresentavam aumento de volume no abdômen foram sacrificados, e os parasitos, retirados da cavidade abdominal. Para preparação do antígeno bruto, os parasitos íntegros foram lavados exaustivamente por sedimentação em PBS-inibidores e homogeneizados (homogeneizador do tipo Potter, da Pyrex Laboratory Glassware, Corning, EUA), em banho de gelo, utilizando-se $20 \mathrm{ml}$ de PBS. Os extratos obtidos foram submetidos a tratamento por ultrasom, 20khz, $1 \mathrm{~mA}$, por quatro períodos de 60 segundos, em banho de gelo. As misturas foram centrifugadas a $15.000 \mathrm{~g}$ por 30 minutos. O sobrenadante obtido foi novamente centrifugado, e ao segundo sobrenadante foram adicionados os inibidores de protease (PMSF - fluoreto de fenilmetilsufonil e iodoacetamina) na concentração de $100 \mathrm{mg}(0,25 \mathrm{mM})$ por mililitro de extrato antigênico. Os antígenos foram divididos em alíquotas e conservados a $-20^{\circ} \mathrm{C}$.

$\mathrm{O}$ antígeno bruto foi passado em coluna de filtração em gel (PD-10 Sephadex G-25M), para retirar os inibidores e equilibrar o extrato bruto com o mesmo tampão da coluna de concanavalina (Con A). Posteriormente, foi purificado por cromatografia de afinidade em coluna de Con ASepharose 4B (Pharmacia Fine Chemicals). O material foi aplicado à coluna, equilibrado com tampão Tris- $\mathrm{HCl} / \mathrm{NaCl}$ 
pH 7,4 (0,5M de $\mathrm{NaCl}$ e 0,05M de Tris), e eluído com solução de alfametilmanosídeo $0,2 \mathrm{M}$. O pico protéico foi concentrado por ultrafiltração em membrana YM-10 (Amicon Corp. - Scientif Systems Division, MA) (33).

A determinação de proteínas foi realizada empregando-se reagente comercial BCA Protein Assay Reagent (Pierce, Rockford, Illinois, EUA), seguindo-se as recomendações do fabricante.

\section{Eletroforese em gel de poliacrilamida utilizando-se dodecilsulfato de sódio (SDS-page) e Western blot (33)}

Foi utilizado um gel de separação contendo $12 \%$ de acrilamida, e a eletroforese foi feita em um sistema vertical (Mini Protean II Dual Slab Cell Rad). O antígeno glicoprotéico na concentração de $0,43 \mu \mathrm{g} / \mu \mathrm{l}$ foi inicialmente dissociado por aquecimento a $100^{\circ} \mathrm{C}$ em tampão Tris$\mathrm{HCl}$ contendo SDS a $1 \%$, mercaptoetanol a $10 \%$ e azul de bromofenol, por dois minutos. Foram utilizados marcadores de baixo peso molecular (14,300-200,00 GibcoBRL).

Para a separação eletroforética foi aplicada corrente de $10 \mathrm{~mA}$ no gel de empilhamento e $20 \mathrm{~mA}$ no gel de separação. Os géis foram então corados pela prata ou eletrotransferidos para membrana de nitrocelulose $(0,2 \mu \mathrm{m})$, por uma hora, a 40mA.

Para a técnica $\mathrm{Wb}$ as membranas de nitrocelulose contendo os antígenos glicoprotéicos foram lavadas quatro vezes por um minuto com tampão Tris- $\mathrm{HCl} 0,02 \mathrm{M} \mathrm{NaCl}$ $0,5 \mathrm{M} \mathrm{pH}$ 7,5/Tween 20 (Tris- $\mathrm{NaCl} / \mathrm{T}$ ), duas vezes com tampão Tris- $\mathrm{NaCl}$, e cortadas em tiras de $3 \mathrm{~mm}$. Foram então estocadas à temperatura ambiente, entre folhas de papel de filtro, até serem usadas na reação imunoenzimática. No ensaio imunoenzimático, as tiras foram bloqueadas com tampão Tris- $\mathrm{NaCl} / \mathrm{T}$ contendo $5 \%$ de leite desnatado (solução bloqueadora) por 30 minutos e em seguida lavadas três vezes com Tris- $\mathrm{NaCl} / \mathrm{T}$ por cinco minutos cada.

Amostras de soro foram diluídas 1/100 em solução bloqueadora, adicionadas a cada tira e incubadas por uma hora, sob agitação, à temperatura ambiente. As tiras foram então lavadas quatro vezes com Tris- $\mathrm{NaCl} / \mathrm{T}$ por cinco minutos cada. O conjugado (IgG de cabra anti-lgG humano ligada à fosfatase alcalina), diluído 1:3.000 em tampão de bloqueio, foi incubado com as tiras por uma hora, e as mesmas foram lavadas como descrito anteriormente, adicionando-se uma última lavagem com água destilada. A reação foi revelada imergindo-se as tiras na solução reveladora NBT (cloreto de nitro-blue-tetrazólio) - BCIP (sal de 5-bromo-4-cloro-3-indol-fosfato,4-toluidina), dis- solvida em tampão Tris- $\mathrm{HCl} / \mathrm{MgCl}_{2} \mathrm{pH} \mathrm{9,5}$ (Tris-0,1M, $\mathrm{MgCl}_{2}$ 0,005M), e, após nova incubação por 10 a $20 \mathrm{mi}-$ nutos para o aparecimento das bandas, as tiras foram lavadas em água destilada e deixadas secar à temperatura ambiente.

Em cada teste foram incluídos um controle positivo e um controle negativo.

\section{Resultados}

Na Tabela 1 podemos observar que, utilizando-se amostras de soro de 21 pacientes com achados clínicos e laboratoriais de NCC, como TC e presença de anticorpos anticisticerco no LCR, as sensibilidades dos métodos Elisa, utilizando-se como antígeno extrato bruto salino de C. cellulosae (Elisa-Cc), e Wb utilizando-se como antígeno glicoproteínas do C. cellulosae (Wb-Cc) e glicoproteínas do $\mathrm{C}$. longicollis $(\mathrm{Wb}-\mathrm{Cl})$, foram de $71 \%, 86 \%$ e $86 \%$, respectivamente. No $\mathrm{Wb}-\mathrm{Cc}$, apenas três destas 21 amostras testadas (14\%) não apresentaram qualquer reatividade, enquanto que $5 \%$ reagiram com duas bandas, $14 \%$ com três bandas, $19 \%$ com quatro bandas, $14 \%$ com cinco bandas e $33 \%$ com seis bandas. Reatividade para apenas uma banda não foi observada (Tabela 1 e Figura 1). No $\mathrm{Wb}-\mathrm{Cl}$, embora tenha havido reatividade com diversas frações, nós só consideramos significativas aquelas que ocorriam com as bandas de $14 \mathrm{kDa}$ e $18 \mathrm{kDa}$ (Figura 2), uma vez que bandas de elevado peso molecular (PM) foram encontradas em indivíduos com outras infecções, portanto 18 amostras de soro foram reativas neste teste.

Nenhum dos 14 soros utilizados como controles negativos apresentou reatividade por qualquer um dos três métodos.

$\mathrm{Na}$ análise dos 22 soros de pacientes com NCC diagnosticada após avaliação clínica e tomográfica, observamos que apenas um destes pacientes, cuja TC mostrou apenas calcificações, apresentou as formas transicional entre as formas ativa e inativa da doença, caracterizada por LCR inflamatório (elevação dos níveis de lgG e título alto de anticorpos anticisticerco). Ele também apresentou título elevado de anticorpos anticisticerco no soro pelo Elisa-Cc, e no Wb-Cc foram observadas as seis bandas diagnósticas. Dois outros pacientes, cujas TCs mostraram também apenas calcificações, apresentaram igualmente a forma transicional da doença, mas não houve correlação com o soro. Em outro paciente com a forma transicional da doença, visualizaram-se edema pela TC e LCR inflamatório, associados a títulos elevados de anticorpos anti- 


\section{Tabela 1 Relação entre valores do Flisa e bandas diagnósticas pelo Wb}

\begin{tabular}{|c|c|c|c|c|c|c|}
\hline \multirow[t]{2}{*}{ Casos } & \multicolumn{2}{|c|}{ Elisa-Cc* } & \multicolumn{2}{|l|}{$\mathrm{Wb}-\mathrm{Cc} * *$} & \multicolumn{2}{|c|}{$\mathrm{Wb}-\mathrm{Cl}^{* * *}$} \\
\hline & UE & Diagnóstico & Bandas & Diagnóstico & Bandas & Diagnóstico \\
\hline 1 & 15 & - & Negativo & - & Negativo & - \\
\hline 2 & 24 & - & Negativo & - & Negativo & - \\
\hline 3 & 181 & + & Negativo & - & Negativo & - \\
\hline 4 & 201 & + & $50,42-39,24,21,18,14$ & + & 14 & + \\
\hline 5 & 132 & + & $50,42-39,24$ & + & 14 & + \\
\hline 6 & 258 & + & $50,42-39,24,21,18,14$ & + & 14 & + \\
\hline 7 & 213 & + & $50,42-39,24,21,18,14$ & + & 14 & + \\
\hline 8 & 198 & + & $50,42-39,24,21,18,14$ & + & 14 & + \\
\hline 9 & 127 & + & $50,42-39,24,21,18,14$ & + & 14 & + \\
\hline 10 & 86 & - & $50,42-39$ & + & 14 & + \\
\hline 11 & 87 & - & $50,42-39,24,21$ & + & 14 & + \\
\hline 12 & 129 & + & $50,42-39,24,14$ & + & 14 & + \\
\hline 13 & 292 & + & $50,42-39,24,21,18,14$ & + & 14 & + \\
\hline 14 & 84 & - & $50,42-39,24$ & + & 14 & + \\
\hline 15 & 162 & + & $50,42-39,24,21$ & + & 14 & + \\
\hline 16 & 119 & + & $50,42-39,24,21$ & + & 14 & + \\
\hline 17 & 173 & + & $50,42-39,24,21,14$ & + & 14 & + \\
\hline 18 & 119 & + & $50,42-39,24,21,14$ & + & 14 & + \\
\hline 19 & 137 & + & $50,42-39,24,21,14$ & + & 14 & + \\
\hline 20 & 66 & - & $50,42-39,24$ & + & 14 & + \\
\hline 21 & 191 & + & $50,42-39,24,21,18,14$ & + & 14 & + \\
\hline
\end{tabular}

*Método Elisa utilizando-se como antígeno extrato bruto salino de C. cellulosae; **método Wb utilizando-se como antígeno glicoproteínas do C. cellulosae; ***método Wb utilizando-se como antígeno glicoproteínas do C. Iongicollis. Os resultados do Elisa foram expressos em unidade imunoenzimática arbitrariamente definida (UE). As amostras foram consideradas positivas quando os resultados foram acima de 100UE (valor de referência = cut-off).

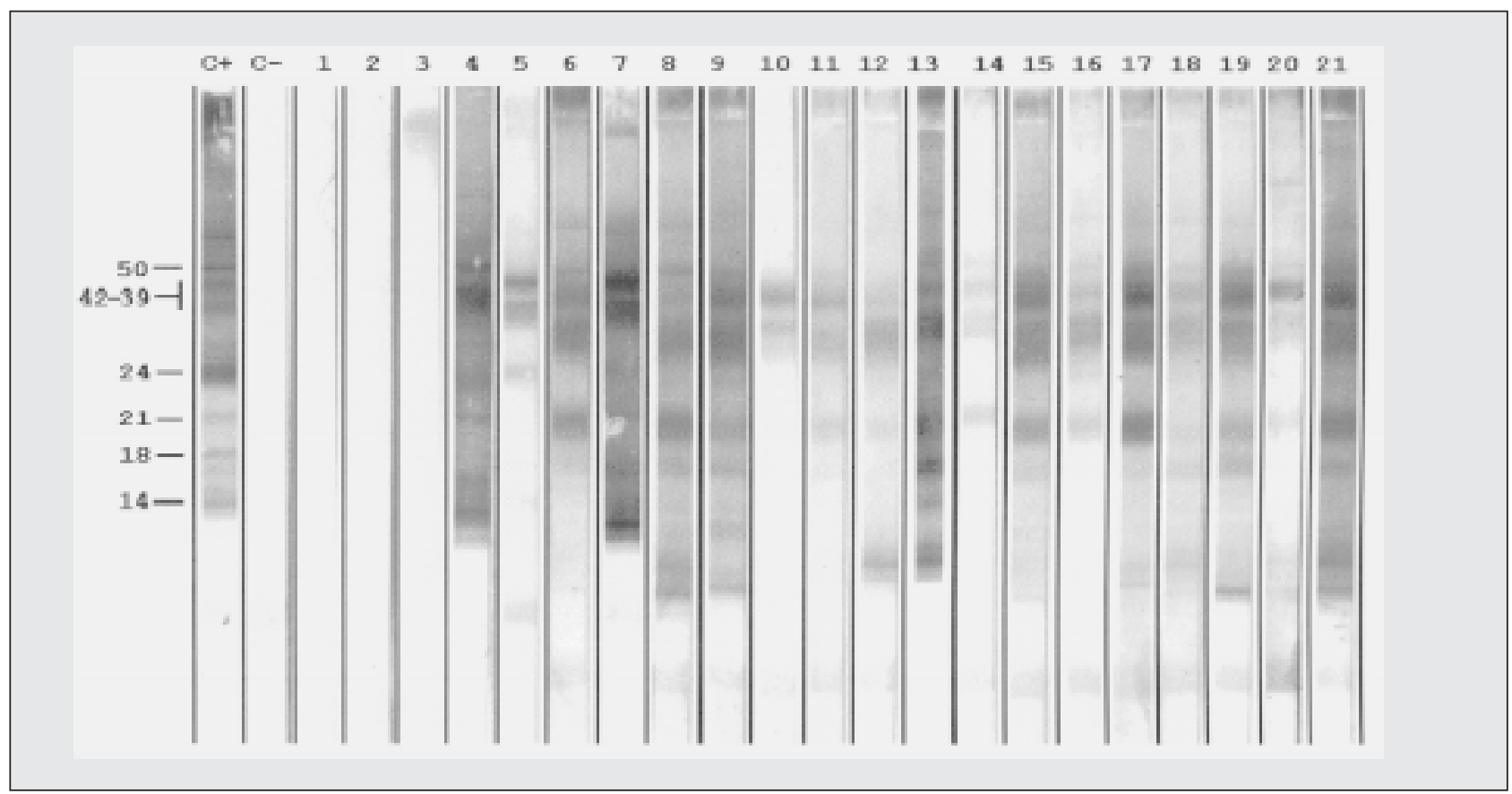

Figura 1 - Wb de 21 amostras de soro de pacientes com NCC utilizando-se como antígeno glicoproteínas de C. cellulosae. C+: controle positivo; C-: controle negativo; 1 a 21: pacientes 


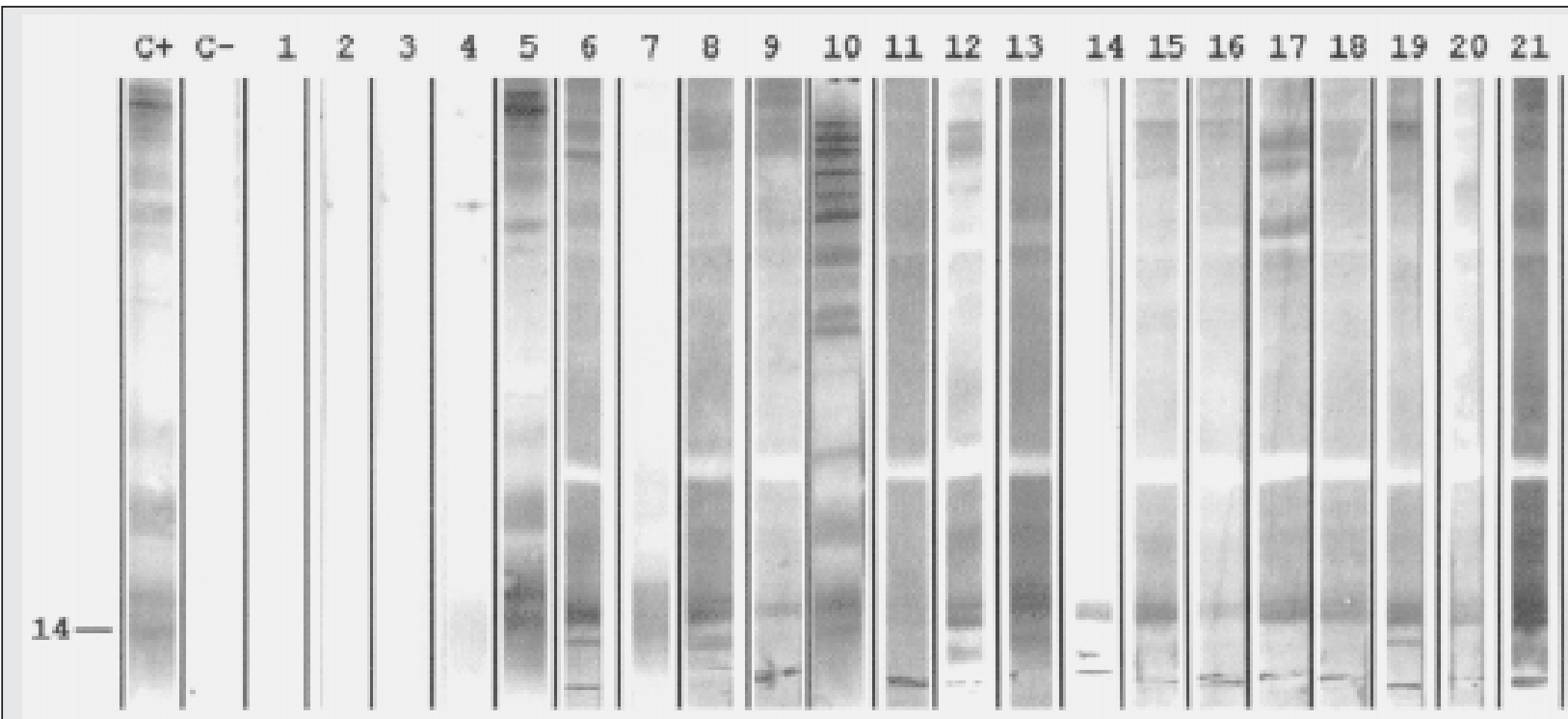

Figura 2 - Wb de 21 amostras de soro de pacientes com NCC utilizando-se como antígeno glicoproteínas de C. Iongicollis. C+: controle positivo; C-: controle negativo; 1 a 21: pacientes

cisticerco no soro, mas apenas pelo método de Elisa. Dezesseis pacientes cuja TC detectou apenas calcificações, um paciente com imagem de cisto único e outro com imagem de cisto em degeneração, não apresentaram alteração no LCR nem no soro.

Na Tabela 2 observa-se que dois dos cinco casos de portadores de Taenia sp. apresentaram sorologia positiva por Elisa-Cc, mas dos quatro soros testados apenas um foi reativo pelo $\mathrm{Wb}-\mathrm{Cc}$, apresentando reatividade para a banda de $42-39 \mathrm{kDa}$, e outro pelo $\mathrm{Wb}-\mathrm{Cl}$, apresentando reatividade para a banda de $14 \mathrm{kDa}$, enquanto que os oito casos de teníase por T. saginata foram negativos pelos três métodos. Os três casos de hidatidose testados foram positivos por Elisa-Cc, com valores elevados de $\mathrm{UE}$, e negativos pelo $\mathrm{Wb}-\mathrm{Cc}$ e $\mathrm{Wb}-\mathrm{Cl}$.

A análise dos outros 213 soros referentes a 11 diferentes parasitoses intestinais mostrou seis soros positivos por ELISA-Cc, porém com valores próximos aos do cut-off. Dos 47 soros testados pelo $\mathrm{Wb}-\mathrm{Cc}$ e pelo $\mathrm{Wb}-\mathrm{Cl}$ (incluindo os seis soros positivos pelo Elisa-Cc), nenhum apresentou reatividade. Os métodos Elisa- $\mathrm{Cc}, \mathrm{Wb}-\mathrm{Cc}$ e $\mathrm{Wb}-\mathrm{Cl}$ apresentaram, então, especificidade de $95 \%$, 99\% e 99\%, respectivamente.

\section{Discussão}

Os métodos imunológicos a serem empregados no diagnóstico de qualquer patologia devem apresentar altas sensibilidade e especificidade, utilizar reagentes estáveis, além de ser práticos e econômicos. Em trabalhos epidemiológicos feitos em países em desenvolvimento com alta prevalência de helmintoses, testes com alta especificidade são de grande importância (36).

Como anticorpos específicos da classe lgG estão presentes na maioria dos pacientes com NCC $(19,43)$, os métodos para sua detecção são os mais utilizados na atualidade. Pelas vantagens que oferece, tais como simplicidade de execução e baixo custo, entre outras, o método Elisa para pesquisa de anticorpos específicos da classe lgG (Elisa-G) tem sido muito utilizado nos países latino-americanos para o diagnóstico da NCC e nos estudos epidemiológicos (41). A sensibilidade e a especificidade deste teste, quando avaliadas com amostras de soro, dependem do antígeno e do tipo de ensaio usado, do curso da infecção e da origem do paciente.

Vários laboratórios têm trabalhado na purificação dos antígenos do C. cellulosae, uma vez que a falta de especificidade tem sido atribuída com freqüência ao uso de antígenos complexos (13).

A inespecificidade do método Elisa tem sido relatada quando soros de pacientes com esquistossomose e hidatidose são testados (12). Entretanto, no nosso estudo, somente foi encontrada inespecificidade nos soros de pacientes com hidatidose.

$\mathrm{Na}$ análise do método Elisa com amostras de soro de pacientes com NCC diagnosticada por clínica, TC e presença de anticorpos anticisticerco no LCR, utilizando-se como antígeno extrato bruto salino de C. cellulosae, foi obtida uma sensibilidade de $71 \%$, que está próxima dos valores de $78 \%$ e $74 \%$ descritos na literatura $(8,22)$. 


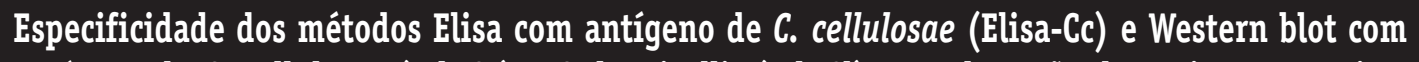
antigeno de $C$. cellulosae $(\mathrm{Wb}-\mathrm{Cc})$ e $\mathrm{C}$. longicollis $(\mathrm{Wb}-\mathrm{Cl})$ para deteç̧ão de anticorpos anti-

Tabela 2 Cysticercus cellulosae em soro

\begin{tabular}{|c|c|c|c|c|c|c|c|c|c|}
\hline \multirow{3}{*}{ Parasitos } & \multirow{3}{*}{$n$} & \multicolumn{4}{|c|}{ Elisa-Cc* } & \multirow{3}{*}{$\begin{array}{r}W b-C c^{*} \\
n\end{array}$} & \multicolumn{3}{|c|}{$\mathrm{Wb}-\mathrm{Cl} * * *$} \\
\hline & & \multicolumn{2}{|c|}{ Negativo } & \multicolumn{2}{|c|}{ Positivo } & & Positivo & $n$ & Positivo \\
\hline & & $<80$ & $80-99$ & $100-120$ & $>120$ & & & & \\
\hline Tsag & 8 & 8 & 0 & 0 & 0 & 5 & 0 & 5 & 0 \\
\hline Tsp & 5 & 3 & 0 & 0 & 2 & 4 & 1 & 4 & 1 \\
\hline$C$ hid & 3 & 0 & 0 & 0 & 3 & 3 & 0 & 3 & 0 \\
\hline $\mathrm{Hn}$ & 5 & 3 & 1 & 1 & 0 & 4 & 0 & 4 & 0 \\
\hline Sm & 5 & 5 & 0 & 0 & 0 & 4 & 0 & 4 & 0 \\
\hline $\mathrm{Al}$ & 49 & 43 & 5 & 1 & 0 & 10 & 0 & 10 & 0 \\
\hline Anci & 35 & 29 & 6 & 0 & 0 & 6 & 0 & 6 & 0 \\
\hline Ss & 14 & 12 & 1 & 1 & 0 & 3 & 0 & 3 & 0 \\
\hline $\mathrm{Tt}$ & 39 & 35 & 3 & 1 & 0 & 8 & 0 & 8 & 0 \\
\hline Ev & 8 & 7 & 0 & 1 & 0 & 4 & 0 & 4 & 0 \\
\hline Eh & 0 & 0 & 0 & 0 & 0 & 0 & 0 & 0 & 0 \\
\hline Ec & 47 & 44 & 0 & 1 & 0 & 8 & 0 & 8 & 0 \\
\hline $\mathrm{Gl}$ & 7 & 7 & 0 & 0 & 0 & 0 & 0 & 0 & 0 \\
\hline $\mathrm{Ib}$ & 4 & 4 & 0 & 0 & 0 & 0 & 0 & 0 & 0 \\
\hline
\end{tabular}

*Método Elisa utilizando-se como antígeno extrato bruto salino de C. cellulosae; **método Wb utilizando-se como antígeno glicoproteínas do C. cellulosae; ${ }^{* * *}$ método Wb utilizando-se como antígeno glicoproteínas do C. longicollis; Tsag: Taenia saginata; Tsp: Taenia sp.; C hid: cisto hidático; Hn: Hymenolepis nana; Sm: Schistosoma mansoni; Al: Ascaris lumbricoides; Anci: ancilostomídeo; Ss: Strongyloides stercoralis; Tt: Trichuris trichiura; Ev: Enterobius vermicularis; Eh: Entamoeba histolytica; Ec: Entamoeba coli; Gl: Giardia lamblia; Ib: Iodamoeba butschlii.

O método Wb para diagnóstico da cisticercose humana tem apresentado sensibilidade e especificidade superiores às encontradas para o Elisa, demonstrando ser um importante método para diagnosticar infecção pela T. solium. Assim como nas outras técnicas imunológicas, também no $\mathrm{Wb}$, o tipo de antígeno utilizado (extratos brutos ou frações purificadas do C. cellulosae) contribui para uma maior ou menor sensibilidade e especificidade do método. Entretanto, nos dias de hoje, há um consenso de que o método $\mathrm{Wb}$, utilizando-se antígeno glicoprotéico purificado de C. cellulosae, por sua alta sensibilidade, alta especificidade e facilidade relativa de execução, deve ser o teste de escolha para o diagnóstico sorológico da cisticercose $(20,21,31)$. Por esse método são identificadas sete bandas glicoprotéicas (50kDa, 42kDa, 24kDa, $21 \mathrm{kDa}, 18 \mathrm{kDa}, 14 \mathrm{kDa}$ e $13 \mathrm{kDa}$ ) específicas para cisticercose por $T$. solium. Como soro de pacientes com hidatidose reage apenas com uma fração de alto PM (70kDa), esse método pode ser usado em regiões onde as duas parasitoses ocorrem com alta incidência. A técnica de $\mathrm{Wb}$ foi capaz de detectar
98\% de casos de cisticercose comprovados parasitologicamente, apresentando dois ou mais cistos, e a especificidade foi de $100 \%$ (34). Em pacientes com lesões únicas, devido à insuficiência de estímulo imune, a sensibilidade cai para $60 \%$ a $80 \%$. Cistos calcificados também são responsáveis por baixa sensibilidade na detecção de anticorpos específicos por esta técnica (36). É importante ressaltar que o método detecta infecção tanto por verme adulto quanto por larva. Como na NCC o tempo entre a aquisição do parasito e o início dos sintomas é longo ( \pm 7 anos) (5), um teste sorológico sensível e específico irá detectar sua presença, permitindo o seu acompanhamento posterior.

Michaulat et al., em 1990, desenvolveram um método utilizando-se como antígeno o C. cellulosae, pelo qual era possível identificar oito bandas ( $\mathrm{PML}<35 \mathrm{kDa})$. Os autores observaram que todas as amostras de pacientes com doença ativa reconheceram a banda de 14kDa. Esta banda não apareceu nas outras doenças parasitárias nem no soro de pacientes com a forma inativa da doença ou com calcificação em progresso. Para doença em fase ativa o 
método apresentou sensibilidade e especificidade de 100\%, valor preditivo positivo e negativo de $100 \%$. Foi também mostrado que soros de pacientes com cisto intraventricular foram positivos apenas para as bandas de $13 \mathrm{kDa}$ e $14 \mathrm{kDa}$, enquanto que soros de pacientes com cisto racemoso reconheceram também a banda de 32kDa (30).

Nossos resultados, obtidos com os soros do grupo de estudo constituído por 21 pacientes com NCC em fase transicional (presença de anticorpos específicos no LCR) e positivos pelo $\mathrm{Wb}-\mathrm{Cc}$, mostram que qualquer uma das seis bandas diagnósticas pode ser observada no soro destes pacientes. Em três dos 21 soros (casos 1 a 3) não foi possível observar correlação entre LCR e soro no que se refere à presença desses anticorpos, o que pode ser explicado pela sua produção intratecal. Todos os soros positivos (casos 4 a 21) reconheceram as bandas de $50 \mathrm{kDa}$ e 42-39kDa. A banda de 24kDa não foi reconhecida por apenas um dos soros (caso 10), e a de $21 \mathrm{kDa}$ foi reconhecida por 13 dos 21 soros (casos 4, 6-9, 11, 13, 15-19, 21). O método apresentou uma sensibilidade de $86 \%$, bem superior à encontrada para o método Elisa-Cc (71\%). Uma possível explicação para termos encontrado uma sensibilidade para o Wb inferior à relatada por Tsang et al. (34) é que alguns desses pacientes podem ter lesão única e, portanto, estímulo imune insuficiente para ser detectado pelo método.

Em um estudo comparativo entre os métodos Elisa e $\mathrm{Wb}$, observou-se que os valores em densidade ótica encontrados nos soros eram significativamente mais altos no grupo que apresentava $\mathrm{Wb}$ positivo para as bandas de $13 \mathrm{kDa}$ e $14 \mathrm{kDa}$, tendo o Elisa apresentado sensibilidade mais alta para os soros deste grupo (20). Dos 18 soros de pacientes com NCC em fase transicional e positivos pelo Wb-Cc que estudamos (casos 4 a 21), 11 reconheceram a banda de $14 \mathrm{kDa}$, correspondendo também a valores mais elevados de UE no método Elisa.

Em vista dos dados apresentados, podemos sugerir que a associação dessas duas técnicas proporciona uma melhoria no diagnóstico da cisticercose humana com igual importância em estudos soroepidemiológicos, nos quais o Elisa pode ser usado para uma seleção inicial e o Wb, como teste confirmatório (9). A utilização de amostras de sangue oferece vantagens em relação à de LCR, pela facilidade de sua obtenção por um processo menos traumático que a punção lombar para contenção do LCR e por oferecer menor risco ao paciente, sendo de grande importância em levantamentos epidemiológicos.
Existem algumas limitações ao se trabalhar com antígenos de cisticercos de T. solium, como dificuldade de obtenção, porque os animais contaminados são mantidos escondidos pelos proprietários; carga parasitária que varia grandemente; dificuldade na retirada desses cistos do músculo de suínos, que é um procedimento trabalhoso e demorado. Por isso antígenos de outros cestodários passaram a ser estudados para o diagnóstico da cisticercose humana. Como os antígenos de C. cellulosae possuem grande homologia com os dos cisticercos da T. crassiceps $(2,15)$, sabe-se, atualmente, que antígenos de $C$. longicollis podem substituir os de $C$. cellulosae nos métodos imunológicos para diagnóstico da cisticercose, tanto no soro (16) quanto no LCR $(17,38-40)$.

Uma vez que esses cisticercos se reproduzem assexuadamente, por gemulação, grande quantidade de cistos pode ser obtida após inoculação de poucos parasitos em cavidade peritoneal de camundongos. Além disso, estes cistos não possuem escólices e, portanto, não é necessário procedimento para separá-los, o que torna o processo de extração do antígeno mais fácil e mais rápido. Todas estas vantagens favorecem a padronização de antígenos de C. longicollis para sua utilização no imunodiagnóstico da cisticercose humana. Antígenos de cisticercos da $T$. crassiceps têm sido usados em diferentes técnicas, principalmente em amostras de LCR, apresentando boas sensibilidade e especificidade (40). Quando empregamos como antígeno as glicoproteínas de $C$. longicollis na técnica Wb em amostras de soro de pacientes com NCC, observamos que esse antígeno apresentou sensibilidade (Tabela 1) e especificidade (Tabela 2) semelhantes às obtidas quando glicoproteínas do C. cellulosae foram empregadas como antígenos, sugerindo que estes antígenos heterólogos podem substituir os homólogos no diagnóstico da doença. A única diferença observada foi que, dos dois pacientes com exame parasitológico de fezes (EPF) positivo para Taenia sp., um foi reativo pelo $\mathrm{Wb}-\mathrm{Cc}$ e outro pelo $\mathrm{Wb}-\mathrm{Cl}$, devido provavelmente à heterogeneidade da resposta imune do hospedeiro.

Embora a introdução da TC tenha fornecido um importante recurso para o diagnóstico da NCC, imagens consideradas positivas podem ter outras causas (1). Confirmação sorológica é freqüentemente necessária para excluir outras doenças infecciosas e não-infecciosas ou lesões neoplásicas no SNC, cujas imagens podem ser bastante semelhantes às encontradas em pacientes com NCC. A ressonância magnética nuclear apresenta maior sensibilidade que a TC na detecção de cisticercos em de- 
terminadas regiões do encéfalo, mas não foi possível a realização deste exame nos pacientes estudados.

Três pacientes com apenas imagens de calcificações pela TC tiveram reação inflamatória significante no LCR. Tais achados estão de acordo com os encontrados na literatura (43), e duas hipóteses podem justificar estes resultados: a TC freqüentemente não mostra cistos localizados na região basal do encéfalo, e as lesões podem não aparecer se os cortes na região de interesse forem maiores que $2 \mathrm{~mm}$ a $4 \mathrm{~mm}$ (1). A TC falhou em demonstrar a fase transicional da doença nestes pacientes, que só foi observada após a análise do soro e do LCR. Com base nesses dados, estes três pacientes foram medicados com albendazol, apresentando considerável melhora clínica. $\mathrm{O}$ sucesso do tratamento sugere que os sintomas eram causados pela presença de cistos não-detectados pela TC.

Nossos dados mostraram que 16 dos 19 pacientes com calcificação no SNC, um paciente com cisto e um paciente com um cisto em degeneração não apresentaram qualquer alteração no LCR ou no soro. O paciente no qual foi detectada presença de edema apresentou resposta inflamatória no LCR, com correspondência no soro. Estes dados estão de acordo com os descritos na literatura, onde vemos que cisto íntegro pode não provocar reação inflamatória e cisto em início de degeneração pode provocar reação inflamatória muito branda, que vai se acentuando à medida que mais antígenos vão sendo liberados pelo parasito, até que volta a ter pouco significado quando começa a calcificação da larva (5).

Os pacientes com a forma transicional da doença apresentaram altos títulos de anticorpos anti-C. cellulosae no LCR e dois deles também no soro. Observamos uma correlação entre os níveis de anticorpos no soro e no LCR.
Nos dois pacientes que tiveram anticorpos detectáveis apenas no LCR, os títulos foram mais baixos que os dos pacientes que também apresentavam anticorpos no soro. Estudo anterior mostrou, da mesma forma, estes resultados falso-negativos no soro, que podem ser devidos à produção intratecal de anticorpos específicos sem correspondência no sangue periférico (6).

Um paciente apresentou alto título de anticorpos específicos no soro e no LCR pelo método Elisa, mas a análise pelo $\mathrm{Wb}$ foi negativa. $\mathrm{O} \mathrm{Wb}$ pode ser negativo em função da localização da lesão $(10,41)$, sendo que lesão intraparenquimatosa única está associada freqüentemente a resultado negativo pelo $\mathrm{Wb}(10)$. O resultado discrepante entre o Elisa e o Wb no soro provavelmente está relacionado às diferenças metodológicas que envolvem as técnicas imunodiagnósticas. Bueno et al. (3) relatam divergências entre os resultados destes métodos, observando que o Elisa, utilizando-se antígeno heterólogo, foi capaz de detectar anticorpos anticisticerco no soro de pacientes com cistos íntegros ou calcificados. Entretanto o $\mathrm{Wb}$ apresentou resultados negativos nestes casos.

Todos os outros pacientes tinham a forma inativa da doença sem título significante de anticorpos no LCR e no soro.

Como a positividade das provas imunológicas e a localização do cisticerco são fatores que determinam o esquema terapêutico, os métodos imunológicos devem ser usados no diagnóstico da NCC $(6,32)$.

\section{Agradecimentos}

Os autores agradecem a Fapesp, Faperj e CNPq.

\section{Referências}

I. Ahuja, G.K. et al. Disappearing CT lesions in epilepsy: is tuberculosis or cysticercosis the cause? J. Neurol. Neurosurg. Psychiatr., 52: 915-6, 1989.

2. Baumeister, S. et al. Comparative serological reactivity of Taenia crassiceps, Taenia solium and Taenia saginata metacestode neutral glycolipids to infection serum from Taenia crassiceps infected mice. Mol. Biochem. Parasitol., 53: 53-6I, 1992.

3. Bueno, E.C. et al. Specific Taenia crassiceps and Taenia solium antigenic peptides for neurocysticercosis immunodiagnosis using serum samples. J. Clin. Microbiol., 38( I): | 46-5 I, 2000.
4. Coker-VAnn, M. et al. Serodiagnosis of human cysticercosis using a chromatofocused antigenic preparation of Taenia solium cysticerci in an enzyme-linked immunosorbent assay (Elisa). Trans. Soc. Trop. Med. Hyg., 78: 492-6, 1984

5. Colli, B.O. et al. Cysticercosis of the central nervous system. Surgical treatment of cerebral cysticercosis. A 23 years experience in the Hospital das Clínicas of Ribeirão Preto Medical School. Arq. Neuro-Psiquiat., 52(2): I66-85, 1994.

6. Del Brutto et al. Neurocysticercosis: an update. Rev. Infect. Dis., 10(6): 1075-87, 1988 
7. Diaz, J.F. et al. Immunodiagnosis of human cysticercosis (Taenia solium): a field comparison of an antibody-enzyme-linked immunosorbent assay (Elisa), and an antigen-Elisa, and an enzime-linked immunoelectrotransfer blot (EITB) assay in Peru. Am. J. Trop. Med. Hyg., 46(5): 61 0-5, 1992.

8. Feldman, M. et al. Comparison of two assay (EIA and EITB) and two samples (saliva and serum) for the diagnosis of neurocysticercosis. Trans. R. Soc. Trop. Med. Hyg., 84(4): 55962, 1990

9. Fritzsche, M. et al. Serological survey of human cysticercosis in Irianese refugee camps in Papua New Guinea. Acta Trop., 47: 69-77, 1990

10. Garcia, H.H. et al. Discrepancies between cerebral computed tomography and Western blot in the diagnosis of neurocysticercosis. Am. J. Trop. Med. Hyg., 50(2): 152-7, 1994.

I I. Garcia, H.H. et al. Serologic evolution of neurocysticercosis patients after antiparasitic therapy.J. Infect. Dis., 175: 486-9, 1997.

12. Girón, E.T. et al. Aplicación del método Elisa para el diagnóstico de la cisticercosis. Bol. Sanit. Panam., 97(1): 8-13, 1984.

13. Katti, M.K. et al. Comparative evaluation of cysticercal antigens and immunoassay in the diagnosis of neurocysticercosis. Ann. Trop. Med. Parasitol., 85(6): 605- 15, 199 I.

14. Katti, M.K. Reliability of immunoassays in diagnosis of neurocysticercosis. J. Clin. Microb., 34(9): 2239, 1996.

15. Kunz, J. et al. Taenia crassiceps metacestode vesicular fluid antigens shared with Taenia solium larval stage and reactive with serum antibodies from patients with neurocysticercosis. Int. J. Med. Microbiol., 27 I: 5 I 0-20, 1989

16. Larralde, C. et al. Deciphering western blots of tapeworm antigens (Taenia solium, Echinococcus granulosus, and Taenia crassiceps) reacting with sera from neurocysticercosis and hydatid disease patients. Am. J. Trop. Med. Hyg., 40(3): 28290, 1989

17. Larralde, C. et al. Immunodiagnosis of human cysticercosis in cerebrospinal fluid: antigens from murine Taenia crassiceps cysticerci effectively substitute those from porcine Taenia solium: arch. Pathol. Lab. Med., I 1 4: 926-8, 1990.

18. Machado, L.R. et al. Computed tomography in neurocysticercosis. Arq. Neuro-Psiquiat., 48(4): 4I 4-8, 1990.

19. Michault, A. et al. Diagnostic immunologique dans le liquide céphalo-rachidien et le sérum de la cysticercose encéphalique évolutive. Pathol. Biol. Paris., 37(4): 249-53, 1989.

20. Michault, A. et al. Apport de l'enzyme-linked immunoelectrotransfer blot assay au diagnostic de la neurocysticercose humaine. Pathol. Biol. Paris, 38(2): I19-25, 1990.

21. Michel, P. et al. Le serodiagnostic de la cysticercose par Elisa et Western blot. Son intérêst et ses limites a Madagascar. Arch. Inst. Pasteur-Madagascar, 57( I): I I 5-42, 1990.

22. Morakote, N. et al. Comparison of cysticercus extract, cyst fluid and Taenia saginata extract for use in Elisa for serodiagnosis of neurocsticercosis. Southeast. Asian J. Trop. Med. Public. Health, 23(1): 77-81, 1992.
23. Placarte,A. et al. Caracterization of GP39-42 and GP24 antigens from Taenia solium cysticerci and of their antigenic GPIO subunit. Parasitol. Res., 85(8-9): 680-4, 1999.

24. Peralta, R.H. et al. Using whole blood collected on filter paper detection of anti-cysticercus antibodies by Elisa. Trans. $R$. Soc. Trop. Med. Hyg., 95: I-2, 200 I.

25. Punzo-Bravo, G. et al. Células plasmáticas en el líquido cefalorraquidiano en pacientes con cisticercosis cerebral. Rev. Invest. Clin., 42(I): 23-8, 1990.

26. Rajshekhar, V. et al. Disappearing CT lesions in Indian patients with epilepsy (letter). J. Neurol. Neurosurg. Psychiatry, 53(9): 818-9, 1990.

27. Rajshekhar, V. et al. Cysticercus immunoblot assay in Indian patients with single small enhancing CT lesions (letter). J. Neurol. Neurosurg. Psychiatry, 54(6): 561-2, 1991.

28. Rodrigues-Canul, R. et al. Epidemiological study of Taenia solium taeniasis/cysticercosis in a rural village in Yucatan state, Mexico. Ann. Trop. Med. Parasitol, 93( I): 57-67, 1999.

29. Romero de Leon, E. et al. A. Oral cysticercosis. Oral. Surg. Med. Oral. Pathol. Oral. Radiol. Endod., 79(5): 572-7, 1995

30. Simac, C. et al. Use of enzyme-linked immunosorbent assay and enzyme-linked immunoelectrotransfer blot for the diagnosis and monitoring of neurocysticercosis. Parasitol. Res., 81: 132-6, 1995.

31. Sloan, L. et al. Evaluation of enzyme-linked immunoassay for serological diagnosis of cysticercosis. J. Clin. Microbiol., 33( I2): 3124-8, 1995.

32. Takayanagui, O.M. \& Leite, J.P. Neurocisticercose. Ver. Soc. Br. Med.Trop., 34(3): 283-90, 2001

33. Teixeira, M.G.M. et al. Development and evaluation of an enzyme linked immunotransfer blot technique for serodiagnosis of Chagas'disease. Trop. Med. Parasitol., 45: 308- 12, 1994.

34.Tsang,V.C.W. et al. An enzyme-linked immunoelectrotransfer blot assay and glycoprotein antigens for diagnosing human cysticercosis (Taenia solium). J. Infect. Dis., I59(I): 50-9, 1989.

35. Tsang, V.C.W. et al. Efficacy of the immunoblot assay for cysticercosis in pigs and modulated expression of distinct: IgM/lgG activities to Taenia solium antigens in experimental infections. Vet. Immunol. Immunopathol., 29: 69-78, I99|

36. Tsang, V.C.W. et al. Taenia solium cysticercosis: an underrecognized but serious public health problem. Parasitol.Today, II (3): |24-6, 1995.

37. Vaz, A.J. \& Ferreira, A.W. Imunodiagnóstico da neurocisticercose: teste imunoenzimático com antígenos quimicamente ligados a suportes para pesquisa de anticorpos em soro e líquido cefalorraquiano. Rev. Inst. Med. Trop. São Paulo, 30: 1-10, 1988.

38. Vaz, A.J. et al. Dot-Elisa for the detection of anti-Cysticercus cellulosae antibodies in cerebrospinal fluid using a new solid phase (resin-treated polyester fabric) and Cysticercus Iongicollis antigens. Rev. Inst. Med. Trop. São Paulo, 38(6): 391 6, 1996.

39. Vaz, A.J. et al. Immunodiagnosis of human neurocysticercosis: use of heterologous antigenic particles (Cysticercus longicollis) in indirect immunofluorescent test. Serodiag. Immunoth. Infect. Dis., 8: |57-61, 1997. 
40. Vaz,A.J. et al. Immunoblot with cerebrospinal fluid from patients with neurocysticercosis using antigen from cystierci of Taenia solium and Taenia crassiceps. Am. J. Trop. Med. Hyg., 57(3): 354-7, 1997.

4I. Vianna, L.G. et al. Estudo comparativo dos testes imunoenzimáticos Elisa-G e Elisa-M, imunofluorescência indireta e fixação de complemento no diagnóstico da cisticercose humana. Arq. Neuro-Psiquiat., 50(3): 302-8, 1992.

42. Walts, A.E. et al. A. Pulmonary cysticercus. Mod. Pathol., 8(3): 299-302, 1995.

43. Zini, D. et al.The relationship of antibody levels to the clinical spectrum of human neurocysticercosis. J. Neurol. Neurosurg. Psychiatry, 53: 656-61, 1990. 